\title{
Framing Analysis of Typo News Reports on Job Creation Through Online News Media
}

\section{Analisis Framing Pemberitaan Typo Undang- Undang Cipta Kerja Melalui Media Pemberitaan Online}

\author{
Deska Rinanti Hayyattun Nuffus ${ }^{1 *}$, Sri Rohaningsih ${ }^{2}$ \\ 1 Jurusan Public Relations - Government Public Relations, Institut Komunikasi dan Bisnis London School of Public \\ Relations, Indonesia, 2 Jurusan Public Relations - Corporate Communication, Institut Komunikasi dan Bisnis London \\ School of Public Relations, Indonesia \\ Jl. Jenderal Soedirman No. Kav. 32, Tanah Abang, Jakarta
}

OPEN ACCESS

ISSN 2541-2841 (online) ISSN 2302-6790 (print)

Edited by: Didik Hariyanto

${ }^{*}$ Correspondence: Deska Rinanti

Hayyattun Nuffus deskarinanti@gmail.co

Citation:

Nuffus, Deska, R. H., and Rohaningsih, Sri (2021)Analisis Framing Pemberitaan Typo Undang-Undang Cipta Kerja Melalui Media Pemberitaan Online, Kanal, 9(3).

Doi:10.21070/kanal.v9i3.1534

\begin{abstract}
The ratification of the Job Creation Law in early November 2020 created a lot of polemics in the society, this leads the news in the online media to have their own views in reviewing typos related to the content in the Job Creation Act. This study aims to unravel the results of media framing from a certain topic by reviewing news coverage by two different online news channels in the same upload period on November 3rd, 2020. The news reconstruction of journalists' points of view creates a gap between empirical truth and public awareness so readers can follow the media thought. The framing analysis was carried out on two news channels, namely CNBC Indonesia and Nasional Tempo, which reported typos in the writing of the Job Creation Law from a different point of view. The method used in this study is from Zhongdang Pan and Gerald M. Kosicki framing analysis model using four structures, namely Syntax, Script, Thematic, and Rhetorical. The results of this study indicate that media coverage of CNBC Indonesia tends to be in line with the government, while the Tempo National media constructs news coverage with a more critical tone. Additionally, other factors in the form of ownership and interests could also affect news framing. This is based on the fact that there is a trend of media conglomeration in Indonesia which can have certain implications for the news content.

Keywords: Omnibus Law on Job Creation; Online Media; Framing Analysis.
\end{abstract}

\begin{abstract}
Abstrak
Pengesahan Undang-undang Cipta Kerja pada awal November 2020 menciptakan banyak polemik di masyarakat, sehingga pemberitaan di media online memiliki pandangannya masing-masing dalam mengulas kesalahan penulisan (typo) terkait isi didalam Undang-undang Cipta Kerja. Penelitian ini bertujuan untuk mengurai hasil framing media dalam membingkai topik tersebut dengan mengulas pemberitaan oleh dua kanal berita online yang berbeda pada periode unggahan yang sama yaitu 03 November 2020. Rekonstruksi sudut pandang penulis berita kedua media menciptakan kesenjangan antara kebenaran empiris dan kesadaran publik agar pembaca bisa mengikuti pemikiran dari media tersebut. Analisis framing dilakukan te-
\end{abstract}


rhadap dua kanal berita yaitu CNBC Indonesia dan Nasional Tempo yang memberitakan kesalahan penulisan UU Cipta Kerja dengan sudut pandang berbeda. Metode yang digunakan dalam penelitian ini adalah Model analisis framing Zhongdang Pan dan Gerald M. Kosicki dengan menggunakan empat struktur yaitu Sintaksis, Skrip, Tematik, dan Retoris. Hasil dari penelitian ini menunjukkan bahwa pemberitaan media CNBC Indonesia cenderung sejalan dengan pemerintah, sedangkan media Nasional Tempo mengkonstruksi pemberitaan mengenai UU tersebut dengan tone yang lebih kritis. Selain itu, adanya faktor lain berupa kepemilikan dan kepentingan yang dapat mempengaruhi framing sebuah berita, hal ini juga didasarkan pada fakta bahwa terdapat trend konglomerasi media di Indonesia yang dapat memberi implikasi tertentu terhadap isi berita.

Kata Kunci: Undang-Undang Cipta Kerja; Media Online; Analisis Framing.

\section{PENDAHULUAN}

Pada tahun 2020 lalu, Pemerintah Indonesia mengeluarkan beberapa kebijakan baru salah satunya yang cukup menarik perhatian publik adalah Undang-Undang (UU) Cipta Kerja atau Omnibus Law Cipta Kerja. Produk hukum ini menimbulkan polemik di kalangan masyarakat sejak awal draft rancangan dikemukakan kepada publik, hingga pembahasan substansi yang menyulut terjadinya demonstrasi besar-besaran di berbagai daerah (Oktaviani, 2020). Terkait isi didalam 15 bab dan 174 pasal didalamnya yang dianggap tidak berpihak pada kepentingan publik, banyak kalangan yang menolak keras rancangan UU Cipta Kerja karena dianggap tidak transparan dan terkesan tergesa-gesa dalam pembahasannya. Banyak masyarakat yang mendaftarkan keluhan terhadap UU ini kepada Mahkamah Konstitusi (MK) dan hal ini juga ditanggapi oleh Presiden Joko Widodo (Jokowi) yang mempersilahkan elemen-elemen masyarakat untuk melaporkan dan mengkaji ulang UU ini ke MK (Intan, 2020).

Ketika UU ini akhirnya disahkan pemerintah pada awal November 2020, kontroversi kembali muncul. Banyak berbagai media mengulas mengenai kesalahan penulisan (typo) dalam UU tersebut yang dianggap sangat gegabah dan tidak profesional. Nurita (2020) melalui kanal berita online Nasional Tempo merilis artikel pada 03 November 2020 dengan judul "Ada 2 Typo di UU Cipta Kerja, Pakar: Semakin Menguatkan Proses yang Ugal-ugalan', sedangkan CNBC Indonesia juga merilis sebuah berita yang ditulis oleh Asmara (2020) pada tanggal yang sama dengan Nasional Tempo yaitu 03 November 2020 dengan judul "Penjelasan Lengkap Istana Soal Salah Ketik di UU Cipta Kerja'. Beritaberita ini rilis dikarenakan adanya informasi terhadap kesalahan pencetakan UU Cipta Kerja yang sudah ditanda tangani oleh Presiden Republik Indonesia, Joko Widodo

Selain itu, melalui penelusuran berita pada media cetak Koran Tempo, adanya kesalahan pengetikan dalam omnibus law juga ditemukan pada Pasal 6 Bab III mengenai Peningkatan Ekosistem Investasi dan Kegiatan Berusaha yang termuat dalam halaman 6 (Nurita, 2020). Dari pemberitaan kedua media sebelumnya, menunjukkan adanya perbedaan dalam pembahasan mengenai kesalahan penulisan yang cukup menyita perhatian. Pemberitaan yang bertolak b- elakang antara kedua kanal berita online ini mengisyaratkan adanya perbedaan framing yang digunakan oleh masingmasing media. Bahasa yang digunakan Nasional Tempo dalam menyampaikan berita lebih mengarah kepada kalimat negatif, sedangkan CNBC Indonesia menyampaikan permasalahan mengenai kesalahan penulisan pada butir dalam UU Cipta Kerja dengan cara pandang yang cenderung positif serta mendukung dan terkesan menegaskan klarifikasi pernyataan dari Istana Negara terhadap Peraturan UU Cipta Kerja tersebut.

Penelitian sebelumnya yang dilakukan oleh Novita, Nur, Rose dan Reyhan (2021) mengenai konstruksi realitas yang dilakukan oleh dua media online, yaitu Online Vivanews dan Tirto.id dalam pemberitaan mengenai UU Cipta Kerja, menyoroti perbedaan kebijakan editorial dan ideologi kedua media. Hasil analisa yang didapat dengan mengurai perbandingan dua dimensi dalam elemen framing Robert $\mathrm{N}$. Entman (2004) dalam (Novita, et. al., (2021) yaitu, penonjolan aspek tertentu dan seleksi isu mengungkap perbedaan nuansa framing oleh kedua media tersebut. Salah satu media cenderung mengulas sisi positif kehadiran UU Cipta Kerja sementara media lainnya menunjukkan keberpihakan kepada masyarakat yang tidak menerima UU Cipta Kerja ini. Hasil analisa yang didapat dengan cara mengurai struktur berita dari pemberitaan oleh kedua media online yang diteliti dengan menekankan penggunaan seleksi isu dan penonjolan aspek tertentu dalam pemberitaannya ternyata memberi implikasi arah framing yang digunakan (Novita. et. al., 2021).

Perbedaan framing yang digunakan keduanya tentu bukan tanpa sebab, mengingat framing sendiri dikonstruksi. Pernyataan tersebut sejalan dengan yang dikemukakan oleh Peter L. Berger dan Thomas Luckmann dalam Eriyanto (2002: 16-17), keduanya menggaris bawahi bahwa realitas sosial merupakan hasil interpretasi atau pemaknaan yang dilakukan manusia sebagai bagian dari integrasinya dengan lingkungannya. Oleh karena itu, pemaknaan yang dihasilkan realitas bisa menjadi sangat subjektif sesuai dengan nilai yang dibangun (Eriyanto, 2002). John A. Fortunato (2008) menjelaskan mengenai framing yaitu framing tidak hanya mengenai pemilihan konten dan paparan kepada audiens tetapi juga pengambilan keputusan tentang cara konten akan disajik- 
an kepada audiens (p.50). Selain itu framing dapat dijelaskan juga sebagai pemikiran yang tidak umum dan merupakan sesuatu yang mencolok serta menjadi fokus oleh pembaca sehingga membuat pembaca mempunyai pandangan dan pemikiran yang berbeda-beda terhadap suatu isu, bahkan bisa sampai membuat reaksi yang tidak terduga (Fortunato, 2008).

Agenda setting dalam pengertian etimologi menurut Ritonga et al. (2018) dapat dipahami sebagai pengaturan atau penyusunan sebuah agenda atau acara ataupun sebuah kegiatan (Ritonga, et. al., 2018). Sedangkan agenda setting dalam pengertiannya menurut Morissan (2013) adalah hubungan yang kuat antara berita yang disampaikan media dengan isu-isu yang dinilai penting oleh publik dan merupakan salah satu jenis dari efek media Massa.

Menurut Lippmann dalam buku Teori Komunikasi oleh Morissan (2013), disebutkan bahwa media bertanggung jawab membentuk persepsi publik. Lippmann juga menegaskan bahwa gambaran realitas yang diciptakan media hanyalah pantulan (reflection) dari realitas sebenarnya dan karenanya terkadang mengalami pembelokan atau distorsi (Morissan, 2013). Sehingga menurut pendapat penulis, dapat disimpulkan dari beberapa pengertian ahli diatas bahwa Agenda Setting merupakan suatu proses pengaturan dari media massa yang berhubungan kuat antara berita nya dengan apa yang dinilai penting oleh publik, dan seringnya mengakibatkan pandangan yang berbeda dan dapat membuat publik mengubah cara pandang mereka, gaya hidup bahkan sampai mempengaruhi kebijakan politik.

Berdasarkan penjabaran sebelumnya yang mengemukakan mengenai framing pemberitaan pada media, penulis tertarik untuk menganalisa lebih lanjut mengenai framing yang dilakukan mengenai pemberitaan terkait kesalahan penulisan pada UU Cipta Kerja yang dimuat oleh kanal media online Nasional Tempo dan CNBC Indonesia. Analisis framing dilakukan untuk mengetahui adanya kemungkinan hubungan antara framing pemberitaan yang ditujukan untuk mempengaruhi keputusan kebijakan yang diambil agar diterima publik.

Beranjak pada penelitian Novita, et. al (2021), peneliti menggunakan cara yang berbeda untuk melihat framing pemberitaan media online yang dimuat oleh CNBC Indonesia dan Kompas.com dengan memfokuskan pada upaya mengurai informasi dibalik pemberitaan kesalahan penulisan dalam UU Cipta Kerja menggunakan metode analisis Zhongdang Pan dan Gerald M. Kosicki. Kajian yang membahas framing oleh media online mengenai UU Cipta Kerja yang menjadi isu populer dalam masyarakat memang telah banyak diulas, mengingat keberadaan UU ini menciptakan polemik tersendiri dalam masyarakat, namun belum ada penelitian yang secara spesifik mengulas tentang pemberitaan kesalahan penulisan UU Cipta Kerja setelah disahkan oleh pemerintah pada November 2020 lalu. Oleh karenanya, penelitian ini diharapkan mampu memberikan pandangan baru sebagai referensi terkait framing media onli- ne mengenai pemberitaan kesalahan penulisan UU Cipta Kerja (Novita. et. al., 2021).

Analisis framing yang akan dilakukan dalam penelitian ini mengacu pada konstruksi sosial yang dibangun oleh kedua kanal berita yang bersumber dari fenomena kesalahan penulisan dalam UU Cipta Kerja. UU ini menarik banyak perhatian khusus dari khalayak karena substansi yang diakomodir terkait kepentingan umum dan isu sensitif di Indonesia yaitu ketenagakerjaan. Selain itu penelitian ini juga akan dijabarkan dengan metode Analisis Framing, Zhongdang Pan \& Gerald M. Kosicki (1993) dalam Eriyanto (2002) yang mengartikan metode ini sebagai proses dalam pembuatan sebuah pesan menjadi lebih menonjol, sehingga menempatkan sebuah informasi lebih utama dibanding yang lainnya dan membuat masyarakat lebih tertuju pada pesan tersebut (Eriyanto, 2002).

Dari penyampaian model framing oleh Pan \& Kosicki dalam Eriyanto (2002), bagaimana cara seseorang memaknai dan menafsirkan suatu pemberitaan dapat diketahui dari empat elemen perangkat framing yaitu (1) Sintaksis yang menjelaskan bagaimana cara pengambilan berita dan penyusunan fakta oleh wartawan, (2) Skrip adalah bagaimana wartawan mengisahkan dan membuat alur sebuah berita, (3) Tematik adalah bagaimana penulis atau wartawan menyampaikan cara pandangnya melalui sebuah berita, dan (4) Retoris adalah bagaimana wartawan memaknai arti dari sebuah berita (Eriyanto, 2002).

\begin{tabular}{|c|c|c|}
\hline STRUKTUR & PERANGKAT FRAMING & UNIT YANG DIAMAT \\
\hline $\begin{array}{l}\text { SikTAKSIS } \\
\text { Cara wartaman } \\
\text { menyutun fakta }\end{array}$ & 1. 5КЕMA ВСRTA & $\begin{array}{l}\text { Headline, Lesd, Latar Informasi, } \\
\text { Kutipan, Sumber, Pernyataan, } \\
\text { Penutup. }\end{array}$ \\
\hline SKRIP & 2. Kelengkapan Berita & $5 W+1 H$ \\
\hline $\begin{array}{l}\text { TEMATIK } \\
\text { Cara Wartawan } \\
\text { menulis takta }\end{array}$ & $\begin{array}{l}\text { 3. Detail } \\
\text { 4. Koherensi } \\
\text { 5. Bentuk Kalimat } \\
\text { 6. Kata Ganti }\end{array}$ & $\begin{array}{l}\text { Paragraf, proposisi, kalimat, } \\
\text { hubungsn antar kalimat }\end{array}$ \\
\hline RetORIS & $\begin{array}{l}\text { 7. Leksikon } \\
\text { 8. Grafis } \\
\text { 9. Metafora }\end{array}$ & Kata, idioen, gambar/foto, grafik \\
\hline
\end{tabular}

\section{METODE PENELITIAN}

Penelitian ini menggunakan studi literatur terhadap pemberitaan yang dimuat di media online mengenai kesalahan penulisan dalam UU Cipta Kerja, yang dilakukan pada periode 03 November 2020. Metode deskriptif kualitatif digunakan dalam studi ini dengan pengumpulan data yang berasal dari berbagai literatur antara lain artikel, jurnal, buku, berita online dan sumber lainnya mengenai pemberitaan kesalahan penulisan dalam UU Cipta Kerja. Teknis analisis data yang dipakai menggunakan tiga tahap sesuai dengan yang dikemukakan oleh Miles, Huberman \& Saldana (2014) kondensasi data, penyajian data dan penarikan kesimpulan (Miles, et. al., 2014). Objek yang dikaji dalam penelitian ini adalah framing pemberitaan mengenai kesalahan penulisan UU Cipta Kerja oleh CNBC Indonesia dan Nasional Tempo. 
Metode analis framing dari Zhongdang Pan \& Gerald M. Kosicki dipilih karena menekankan pada dua konsep tersebut (psikologi dan sosiologis) yang membuat penulis berita mengarahkan fokus masyarakat pada tulisan yang dibuatnya. Sejak awal kemunculan rancangan UU Cipta Kerja hingga kemudian disahkan dan terdapat kesalahan penulisan pada UU yang telah disahkan, keberadaannya menciptakan kegaduhan ditengah masyarakat sehingga terdapat kemungkinan framing oleh media yang diarahkan pada upaya tertentu agar pembaca mengikuti pemikiran media dalam menyikapi kesalahan penulisan UU Cipta Kerja. Sehingga metode ini dianggap memudahkan rekonstruksi peneliti dalam menafsirkan informasi dibalik pemilihan sudut pandang pemberitaan yang dipakai oleh kedua media yang dipilih.

\section{HASIL DAN PEMBAHASAN}

Dari hasil analisa peneliti terhadap pemberitaan CNBC Indonesia, disimpulkan bahwa mengacu kepada elemen pertama dari Pan \& Kosicki (1993) dalam Eriyanto (2002) yang menjelaskan mengenai Struktur Sintaksis pada pemberitaan oleh CNBC Indonesia antara lain menampilkan Headline"Penjelasan Lengkap Istana Soal Salah Ketik di UU Cipta Kerja", dengan Lead berita yang digunakan mengacu pada perspektif berita yang berasal dari sudut pandang Pemerintah melalui pernyataan Menteri Sekretaris Negara Pratikno. Latar informasi berita ini merupakan wawancara di Istana Negara oleh wartawan CNBC Indonesia dengan menggunakan sumber kutipan hanya berasal dari pernyataan Menteri Sekretaris Negara Pratikno dan tidak terdapat opini penulis lainnya sehingga pernyataan yang diungkapkan dalam bagian penutup pun masih menggunakan nuansa yang sejalan yaitu "Pratikno lantas mengakui bahwa telah terjadi kekeliruan teknis penulisan UU 11/2020 tersebut. Namun, kekeliruan tersebut sama sekali tidak mengubah apapun substansi dalam UU Cipta Kerja".

Elemen kedua selain sintaksis, berupa skrip yang menjelaskan mengenai struktur substansi dalam paragraf yang menurut pengamatan peneliti lebih menekankan pembahasan berdasarkan sudut pandang Menteri Sekretaris Negara sebagai sumber informasi.

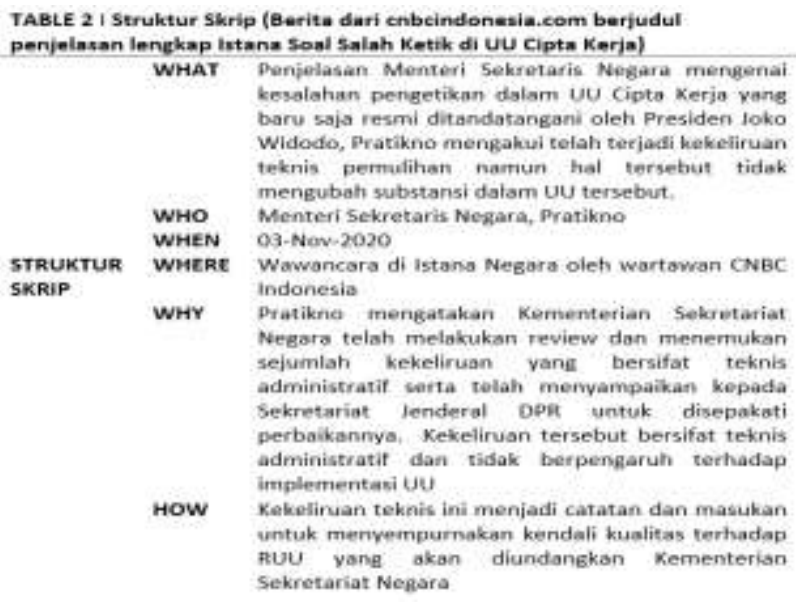

Pada elemen tematik, Pan \& Kosicki dalam Eriyanto (2002) membahas mengenai detail, koherensi, bentuk kalimat dan kata ganti yang digunakan dalam pemberitaan. Pada pemberitaan ini terdapat paragraf yang diarahkan penulis untuk mendukung pernyataan Istana dengan penekanan terhadap upaya perbaikan penulisan dan mengesampingkan dampak hukum logis dari kekeliruan penulisan sebagai kesalahan administratif semata. Unsur tematik dibuktikan dengan penggunaan kata 'namun', 'sehingga', 'terus menyempurnakan', 'untuk', 'agar', 'tidak...lagi'.

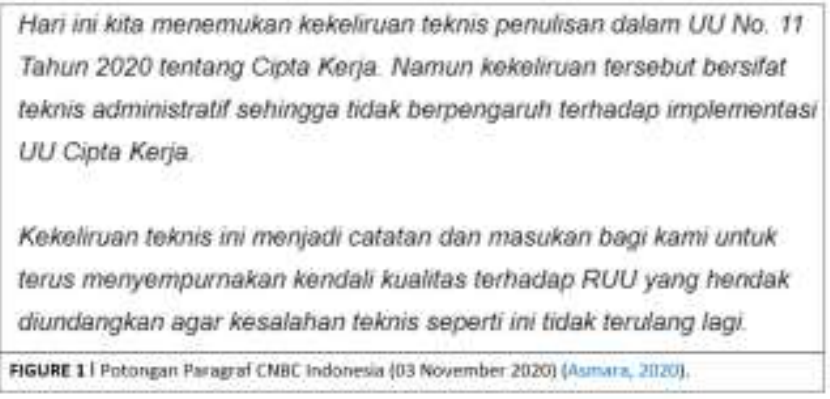

Berlawanan dengan analisa pada pembahasan Nasional tempo, struktur sintaksis yang digunakan melalui Headline pada Nasional tempo adalah "Ada 2 Typo di UU Cipta Kerja, Pakar: Semakin Menguatkan Proses yang Ugalugalan". Sedangkan pada Lead berita menggunakan pernyataan pakar hukum yang dianggap memiliki kredibilitas untuk merepresentasikan gambaran realitas pada isu kesalahan penulisan UU Cipta Kerja. Selain itu, latar informasi berita dalam kanal berita ini hanya berasal dari pendapat Pakar Hukum Tata Negara, Bivitri Susanti. Dominasi sumber kutipan hanya berasal dari pendapat serta ulasan Bivitri Susanti, tanpa penambahan opini dari penulis berita. Pernyataan pada penutup berita digunakan untuk menegaskan konstruksi pemikiran penulis dengan memasukkan kembali pendapat dari Bivitri Susanti yang menyatakan "Seakan-akan mengerdilkan makna pembuatan UU, padahal UU itu seperti kontrak sosial warga melalui wakil-wakilnya. Ini akibatnya kalau tujuan buruk menghalalkan segala cara".Struktur skrip yang terdapat pada pemberitaan oleh kanal berita Nasional Tempo merupakan strategi penulis berita dalam mengemas peristiwa ke dalam bentuk berita. Pengemasan berita pada Nasional Tempo lebih banyak bercerita mengenai penekanan kesalahan typo pada UU tersebut. Hal ini seolah mengarahkan pembaca untuk lebih kritis menyoroti kesalahan penulisan UU tersebut sebagai isu krusial.

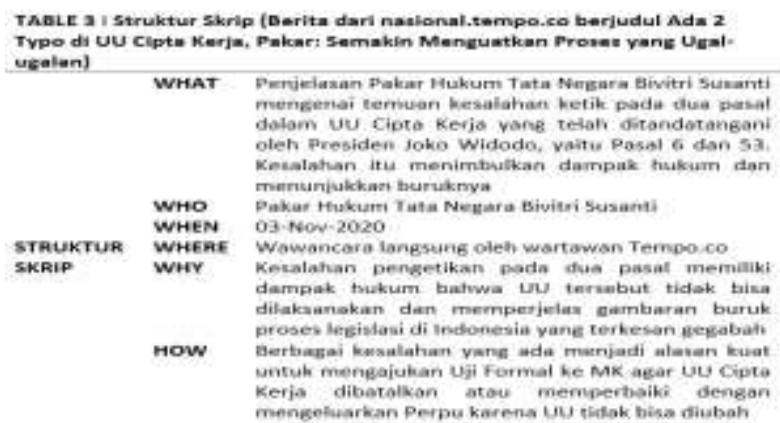
dampak bukum batwe UU terambut tidek bisa dilakasnokan dan memperjelas gamberan buruk proses legsistasi di indonesia yane terkesan gegaboh.

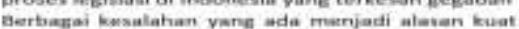

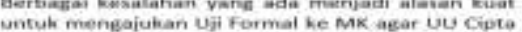
Keri. dibetolkon atou memperthaik dengon mengetuarkan Perpu kerena $4 M$ sidak hisa diubah 
Elemen tematik secara keseluruhan dirancang untuk mengarahkan pembaca agar sejalan dengan konstruksi penulis berita ini. Penggunaan detail informasi yang lebih menekankan unsur dalam UU yang dianggap memiliki kesalahan fatal, diperkuat dengan penggunaan kata ganti antara lain 'terdapat', 'tidak bisa lagi' dan 'seperti'.

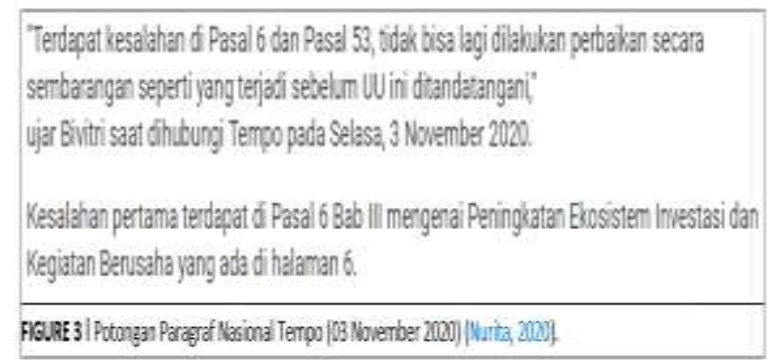

Lebih lanjut, untuk elemen retoris pada pembahasan berita Nasional Tempo penggunaan Leksikon (pemilihan kata) banyak mengambil dari penjelasan Pakar Hukum Tata Negara, Bivitri Susanti.

Sedangkan Grafis (pemakaian gambar) menampilkan foto demonstrasi menolak UU Cipta Kerja di kawasan Patung Kuda Jakarta, pada Senin, 2 November 2020 untuk menegaskan tematik yang dipakai oleh penulis berita. Sedangkan Metafora (penggunaan ungkapan) yang terdapat pada Judul dengan menggunakan kata "Ugal-ugalan" merupakan bagian yang mempertajam upaya penulis berita untuk menggiring pembaca agar sejalan dengan penulis.

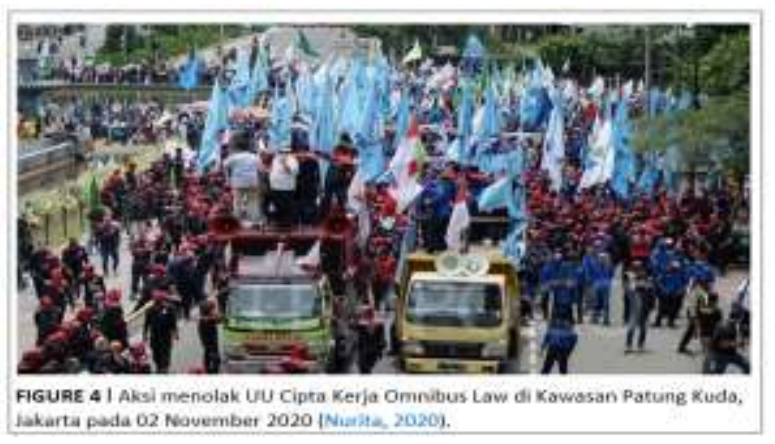

Kanal berita online Nasional Tempo dan CNBC Indonesia sama-sama dimiliki oleh jaringan media besar di Indonesia yang memiliki peran besar dalam pemberitaan peristiwa yang menyita perhatian publik luas, tidak terkecuali pada pemberitaan mengenai UU Cipta Kerja. Sejak awal RUU Cipta Kerja digelontorkan hingga disahkan pada November 2020 lalu, banyak polemik yang menyertai. Kesalahan penulisan yang terdapat dalam UU Cipta Kerja yang telah disahkan ternyata disikapi berbeda oleh kanal berita yang berbeda pula.

Perbedaan Framing yang digunakan oleh CNBC Indonesia dan Nasional Tempo dalam pemberitaan mengenai kesalahan penulisan pada UU Cipta Kerja lebih lanjut oleh penulis dijabarkan sebagai berikut, untuk framing pada kanal berita online CNBC Indonesia mengenai adanya typo pada UU Cipta Kerja yang baru saja disahkan oleh Presiden Joko Widodo dibentuk sebagai pemberitaan yang hanya memberi- kan penjelasan secara umum mengenai kesalahan penulisan.

Pemberitaan cenderung memposisikan kesalahan sebagai hal yang biasa dan berdalih secara halus dengan mengkategorikannya sebagai kesalahan teknis administratif. Hal ini dibuktikan dengan struktur sintaksis pemberitaan yang menggunakan lead dengan perspektif berita yang berasal dari pernyataan Menteri Sekretaris Negara dan dipertegas dengan struktur tematik pemberitaan menggunakan pemilihan kata yang menyatakan secara jelas mengenai kesalahan penulisan sebagai hal biasa, antara lain "namun", "sehingga tidak berpengaruh". Untuk struktur retoris ditunjukkan melalui pernyataan penutup yang mendorong publik untuk bersikap biasa menyikapi kesalahan penulisan UU.

Sedangkan temuan peneliti terhadap framing yang dirancang penulis berita Nasional Tempo dalam mengulas tentang kesalahan penulisan pada UU Cipta Kerja lebih menitikberatkan pada dampak hukum dari kesalahan penulisan UU Cipta Kerja dan proses pembuatan UU itu sendiri yang dirasa tidak beraturan. Struktur sintaksis headline dan lead pemberitaan menggunakan sudut pandang yang mengkritik kesalahan penulisan UU Cipta Kerja dengan judul "Ada 2 Typo di UU Cipta Kerja, Pakar: Semakin Menguatkan Proses yang Ugal-ugalan". Struktur tematik menjabarkan dengan gamblang kesalahan penulisan yang terdapat dalam 2 Pasal pada UU Cipta Kerja serta akibat hukum yang ditimbulkannya, dan langkah yang bisa diambil dengan mengeluarkan Peraturan pengganti Undang-undang (Perpu). Struktur retoris dibuktikan dengan penggunaan kata "ugalugalan", "sembarangan", dan "seakan-akan mengerdilkan". Secara keseluruhan dapat ditarik kesimpulan mengenai framing pemberitaan milik kanal berita Nasional Tempo cenderung mengarahkan pembaca agar mengkritisi dan memberikan penilaian negatif terhadap pengesahan UU Cipta Kerja ini.

Hal tersebut diperkuat dengan detail penyampaian ulasan hukum dalam paragraf pada pemberitaan media online Nasional Tempo, serta adanya penekanan dengan penggunaan gambar demonstrasi yang pernah dilakukan. Penekanan tertentu pada suatu bagian dalam berita, dimaksudkan untuk membuat salah satu bagian dalam informasi yang disajikan dapat terlihat jelas dan mudah diterima oleh publik bila dibandingkan penyajian secara biasa (Hariyanto \& Kharina, 2018). Dapat dikatakan bahwa, hal ini dilakukan secara sengaja oleh jurnalis sebagai bentuk kritik dan upaya untuk mendorong kesadaran publik agar lebih memberi perhatian khusus pada isu kesalahan penulisan UU Cipta Kerja.

Dapat kita lihat dari uraian diatas bahwa masing-masing media membuat agenda setting tersendiri dengan menampilkan perspektif berbeda terhadap topik yang sama mengenai kesalahan penulisan pada UU Cipta Kerja yang sedang menjadi perhatian atau sorotan masyarakat melalui pemberitaan yang berulang. Pemberitaan diarahkan agar publik merespon berbeda terhadap isu tersebut. Tentu respon yang diharapkan ini tergantung dari tujuan berbeda yang ingin disampaikan oleh masing-masing media. 
Selain menggunakan metode analisis framing dari Zhongdang Pan \& Gerald M. Kosicki (1993) dalam Eriyanto (2002), penulis juga menganalisis melalui beberapa faktor hubungan yang mungkin dapat mendasari adanya perbedaan cara pemberitaan pada Nasional Tempo dan CNBC Indonesia, yaitu (1) Hubungan Kepemilikan, CNBC Indonesia merupakan media online yang terafiliasi dengan CNBC Internasional. Menurut situs resmi nya CNBC Indonesia merupakan bagian dari detiknetwork di bawah Grup Transmedia yang dimiliki oleh Chairul Tanjung. (Tentang Kami, n.d.). Dalam perjalanannya, pendiri Grup Transmedia yaitu Chairul Tanjung merupakan sosok pendukung Presiden Jokowi, hal ini dapat diketahui ketika Jokowi mengangkat anak sulung Chairul Tanjung menjadi salah satu anggota staf khusus Presiden, yaitu Putri Indahsari Tanjung (Sukirno, 2019).

Sedangkan untuk Nasional Tempo atau yang lebih dikenal dengan Tempo.Co merupakan media informasi yang dikenal independen. Pendiri dari media Tempo adalah Harjoko Trisnadi, Fikri Jufri, Lukman Setiawan, dan Bur Rasuanto, Goenawan. Filosofi yang dianut oleh media Tempo mengedepankan jurnalisme yang tidak berpihak dengan nilai budaya yaitu terpercaya, merdeka, dan profesionalitas (tempo.id). Hal ini dibuktikan dari sejarah panjang Tempo yang pernah beberapa kali dibredel oleh rezim pemerintah saat itu (tempo.id). Tempo menurut Nurhajati \& Wijayanto (2019) adalah salah satu media yang mempunyai self-regulation, dimana dalam kegiatannya para pemilik tidak dapat terikat sehingga dapat memisahkan antara kepentingan kepemilikan dan kegiatan jurnalisnya (Nurhajati \& Wijayanto, 2019). Tentunya hal ini sejalan dengan sikap ideal media yang seharusnya tidak memihak kepada kepentingan apapun dan siapapun termasuk kepentingan pemilik media sekalipun sesuai yang diatur dalam Undang-undang Pers Nomor 40 tahun 1999 mengenai Pers Indonesia yang harus bersikap independendan dalam penyajian berita dan menyampaikan berita tanpa intervensi pihak manapun.

\begin{tabular}{|c|c|c|}
\hline \multicolumn{3}{|c|}{$\begin{array}{l}\text { TABLE } 4 \text { I Persentase Pemegang Saham Tempo Inti Media, data olahar } \\
\text { peneliti (2021) diambil dari Aktivitas Pasar } \\
\text { (https://www.idnfinancials.com/id/tmpo/pt-tempo-inti-media-tbk) }\end{array}$} \\
\hline PEMEGANG SAHAM & JUMLAH SAHAM & PRESENTASE \\
\hline Public (each below 5\%) & 266.119.881 (Saham) & $25,15 \%$ \\
\hline PT Grafiti Pers & 256.960 .003 (Saham) & $24,28 \%$ \\
\hline Yayasan Tempo 21 Juni 1994 & 181.322 .500 (Saham) & $17,13 \%$ \\
\hline PT Jaya Raya Utama & 172.329.205 (Saham) & $16,28 \%$ \\
\hline Yayasan Jaya Raya & 90.429.394 (Saham) & $8,54 \%$ \\
\hline Yayasan Karyawan Tempo & 87.627.267 (Saham) & $8,28 \%$ \\
\hline Bambang Harymurti & 2.745 .000 (Saham) & $0,26 \%$ \\
\hline Goenawan S. Muhamad & 800.000 (Saham) & $0,08 \%$ \\
\hline
\end{tabular}

Selanjutnya, (2) hubungan Kepentingan, publik berhak mengetahui informasi apapun mengenai apa sedang terjadi dalam pemerintahan, serta langkah apa yang dilakukan oleh pemerintah. Hal ini merupakan krusial dalam demokrasi pemerintahan. Dalam hal ini peran media menjadi penting se- bagai perpanjangan tangan publik untuk mengakses informasi dan menyebarluaskannya melalui pemberitaan untuk mengakomodir kepentingan publik.

Pada pemberitaan kedua kanal berita tersebut, mereka menyampaikan dari sisi publik bahwa publik ingin lebih mengetahui bagian mana dari UU Cipta Kerja tersebut yang terdapat kesalahan, bagaimana proses sebenarnya, publik juga ingin mengetahui bagaimana tanggapan pihak dari Istana atau Presiden Jokowi yang sudah melakukan legalisasi terhadap UU Cipta Kerja tanpa melakukan pengecekan terlebih dahulu, oleh karena itu isi dari dua media dapat berbeda berdasarkan sasaran publik dan reaksi yang ingin didapatkannya.

Selain itu juga adanya kepentingan media, dimana menurut Fortunato (2008) menyebutkan mengenai pemilihan konten yang diterjemahkan kedalam Bahasa Indonesia yaitu "setelah konten dipilih maka media dibatasi oleh waktu dan ruang dalam menyajikan setiap aspek sebuah cerita. Sebagaimana beberapa berita tidak akan diliput sama sekali, sifat produksi berita bahkan tidak mengizinkan masalah yang dibahas dilakukan dengan standar yang sama.'” (p.50).

Dari penjelasan diatas dapat disimpulkan bahwa sebenarnya dari sebuah pemberitaan ada kepentingan media yang terlibat dalam hal ini. Media akan memilih konten yang dipertimbangkan menurut kepentingannya akan membawa suatu keuntungan bagi media itu sendiri. Lebih lanjut, imbas dari adanya kepentingan yang dimiliki oleh masing-masing pemilik media juga diwujudkan ke dalam konten yang dimuat. Keberadaan media online hanya merupakan perubahan bentuk dari media massa konvensional seperti televisi dan surat kabar, sehingga dengan adanya konglomerasi media dapat berdampak pada keseragaman konten yang dimuat dari masing-masing jaringan pemilik media (Kamelia \& Nusa, 2018).

Pemberitaan yang dimiliki oleh kedua media online yang diambil dalam studi ini tentunya memiliki tujuan masingmasing yang ditetapkan oleh pemilik media dibaliknya. Berbeda dengan dua kepentingan lainnya, peneliti menemukan mengenai adanya keterlibatan kepentingan elit politik, dari dua pemberitaan yang berbeda tersebut ada media yang berpihak kepada elit politik. Menurut peneliti hal ini juga salah satu alasa pemberitaan dapat memuat unsur kepentingan elit politik yang dapat mempengaruhi bagaimana cara rekonstruksi pada pemberitaan.

CNBC Indonesia secara tidak langsung akan mendukung kepentingan Presiden karena adanya hubungan pemilik media dan elit politiknya, sehingga berita yang disampaikan pun cenderung tidak menuliskan sesuatu yang negatif namun cenderung positif ataupun netral. Berbeda dengan kanal berita Nasional Tempo yang memang independen dan sudah sejak lama sering tersandung masalah dan dibredel berkali-kali akibat pemberitaannya mengenai para elit politik, tidak dapat dipungkiri bahwa elit politik juga mengendalikan media sebagai bagian dari upaya untuk dapat mempertahankan citranya di kalangan masyarakat maupun para pendukungnya. 
Sejalan dengan pemikiran pada penelitian Novita et al. (2021) yang juga menunjukkan adanya perbedaan kepentingan pada media ketika memuat sebuah berita. Dijelaskan oleh Novita et al. (2021) bahwa Vivanews cenderung menunjukkan sikap yang sangat hati-hati ketika memberitakan hal-hal yang menyangkut kekuasaan karena latar belakang pemiliknya erat dengan lingkup politik, sedangkan kanal berita Tirto.id menurut analisa Novita et al. (2021) lebih aspiratif dengan kepentingan publik yang menonjolkan kecenderungan pemberitaan dengan mengandung unsur penolakan, ketidaksetujuan dan kontroversi (Novita et al., 2021). Lebih lanjut, kedua framing berita telah mencakup semua unsur yang terdapat dalam metode analis framing dari Zhongdang Pan \& Gerald M. Kosicki (1993) dalam Eriyanto (2002).

Beberapa kritik mengenai agenda setting dan framing dari penjelasan oleh Abdelrahman (2020a) yang dapat menambah analisa pada temuan dalam kasus ini antara lain:

1. Agenda setting berarti pemberitaan yang diangkat bukan seluruhnya hal yang sama melainkan dilakukan penyaringan terhadap berita itu sendiri, sehingga akan mempertanyakan kembali keaslian sebuah berita.

2. Adanya informasi yang tidak seluruhnya disampaikan bahkan juga diubah berdasarkan kepentingannya sehingga mempengaruhi tingkat kepercayaan publik terhadap ulasan sebuah berita yang sama dari media yang berbeda.

3. Framing juga menciptakan kesenjangan antara kebenaran empiris dan kesadaran publik melalui rekonstruksi sudut pandang yang dirancang media (Abdelrahman, 2020b).

\section{KESIMPULAN}

Kesenjangan yang ditampilkan dari dua Kanal berita online ini akan semakin besar dengan perkembangan new media yang memberi akses tanpa batas, yang memungkinkan setiap orang menjadi bagian dari citizen journalist. Framing dibuat terhadap pemberitaan realitas sosial, maka selayaknya terus berkembang mengingat realitas sosial cenderung dinamis daripada statis. Lebih lanjut, dalam uraian sebelumnya pada bagian analisis, peneliti memasukkan hubungan kepemilikan dan kepentingan yang dapat mempengaruhi framing sebuah berita. Hal ini didasarkan pada fakta bahwa terdapat trend konglomerasi media yang menurut pendapat peneliti dapat memberi implikasi terhadap isi berita agar diarahkan untuk mendorong opini publik sejalan dengan kepentingan yang diusung pemilik media atau tujuan tertentu.

\section{UCAPAN TERIMAKASIH}

Terima kasih kami ucapkan kepada semua pihak yang telah membantu terciptanya karya ilmiah ini, keluarga tercinta, teman, dan para dosen di Institut Bisnis dan Komunikasi LSPR, serta kepada Jurnal KANAL yang telah memberikan kesempatan untuk penerbitan karya ilmiah ini.

\section{REFERENSI}

Abdelrahman, A. A. (2020a). Agenda Setting. London School of Public Relations Jakarta.

Abdelrahman, A. A. (2020b). Framing. London School of Public Relations Jakarta.

Asmara, C. G. (2020, November 3). Penjelasan Lengkap Istana Soal Salah Ketik di UU Cipta Kerja. CNBC Indonesia. https://www.cnbcindonesia.com/news/20201103142921-4198949/penjelasan-lengkap-istana-soal-salah-ketik-di-uu-cipta-kerja.

Eriyanto. (2002). Analisis Framing; Konstruksi, Ideologi, dan Politik Media (N. H. SA (ed.); 1st ed.). LKIS PELANGI AKSARA. https://play.google.com/books/reader?id=O8xjDwAAQBAJ\&pg=GBS.P $\mathrm{R} 3 \& \mathrm{hl}=\mathrm{en}$.

Fortunato, J. A. (2008). Making Media Content: The Influence of Constituency Groups on Mass Media. Lawrence Erlbaum Associates, Publishers. www.erlbaum.com.

Hariyanto, D., \& Kharina, A. D. (2018). Pemberitaan Pidato Pribumi Anies Baswedan Pada Media Indonesia.Com dan Okezone.Com Preaching of Anies Baswedan's Indigenous Speech to Media Indonesia.Com and Okezone.Com. Kanal Jurnal: Ilmu Komunikasi. https://doi.org/10.21070/kanal.v\%vi\%i.3029.

Intan, G. (2020). Jokowi: Yang Tidak Puas dengan UU Cipta Kerja, Silahkan Ajukan Uji Materi. VOA Indonesia. https://www.voaindonesia.com/a/jokowi-yang-tidak-puas-dengan-uucipta-kerja-silahkan-ajukan-uji-materi/5615331.html.

Kamelia, F., \& Nusa, L. (2018). Pemberitaan Hutang Indonesia Dalam Bingkai Media Online. Kanal Jurnal: Ilmu Komunikasi, 7, 1. https://doi.org/10.21070/kanal.v\%vi\%i.2367.

Miles, M. B., Huberman, A. M., \& Saldana, J. (2014). Qualitative Data Analysis, A Methods Sourcebook-SAGE Publications (3rd ed.). SAGE Publications, Inc.

Morissan. (2013). Teori Komunikasi, Individu Hingga Massa (1st ed.). Kencana, Prenadamedia Group.

Novita, I., Nur, I., Rose, T., \& Reyhan, M. (2021). Konstruksi Realitas Media (Analisis Framing Pemberitaan UU Cipta Kerja Omnibus Law dalam Media Online Vivanews dan Tirto.id). Jurnal Syntax Admiration, 2(1), 6984.

http://jurnalsyntaxadmiration.com/index.php/jurnal/article/view/162/253.

Nurhajati, L., \& Wijayanto, X. A. (2019). Kepemilikan Media dan Isi Pemberitaan Koran Tempo. Jurnal Pewarta Indonesia, 1(1), 1-14. https://doi.org/10.25008/jpi.v1i1.1.

Nurita, D. (2020, November 3). Ada 2 Typo di UU Cipta Kerja, Pakar: Semakin Menguatkan Proses yang Ugal-ugalan. Tempo.Co. https://nasional.tempo.co/read/1401787/ada-2-typo-di-uu-cipta-kerjapakar-semakin-menguatkan-proses-yang-ugal-ugalan.

Oktaviani, Y. (2020). Polemik Omnibus Law Cipta Kerja. Kompas Pedia. https://kompaspedia.kompas.id/baca/infografik/kronologi/polemikomnibus-law-cipta-kerja.

Ritonga, Y. E., Program, Komunikasi, S., Islam, P., Dakwah, F., \& Komunikasi, D. (2018). Teori Agenda Setting dalam Ilmu Komunikasi Theory of Setting Agenda in Communication Science. SIMBOLIKA, 4(1). http://ojs.uma.ac.id/index.php/simbolika.

Sukirno. (2019, November 22). 5 konglomerat penguasa media di balik Jokowi. Alinea.Id. https://www.alinea.id/media/5-konglomerat-penguasa-mediadi-balik-jokowi-b1Xqa9ppQ.

Conflict of Interest Statement: The authors declare that the research was conducted in the absence of any commercial or financial relationships that could be construed as a potential conflict of interest.

Copyright (C) 2021 Nuffus and Rohaningsih. This is an open-access article distributed under the terms of the Creative Commons Attribution License (CC BY). The use, distribution or reproduction in other forums is permitted, provided the original author(s) and the copyright owner(s) are credited and that the original publication in this journal is cited, in accordance with accepted academic practice. No use, distribution or reproduction is permitted which does not comply with these terms. 